\title{
Modifier Based Enhancement in Physical and Chemical Properties of Bitumen (Brief Review)
}

\author{
SONU SHARMA ${ }^{1}$, SITANSH SHARMA ${ }^{2 *}$ and NIRAJ UPADHYAY ${ }^{3 *}$ \\ ${ }^{1}$ Department of Chemistry, Lovely Professional University, Jalandhar, Punjab, India. \\ ${ }^{2}$ Division of Physical Sciences and Engineering, King Abdullah University of Science and Technology, \\ Saudi Arabia. \\ ${ }^{3}$ Department of Chemistry, Dr. Hari Singh Gour University, Sagar, Madhya Pradesh, India. \\ *Corresponding author E-mail: nirajiitr@gmail.com \\ http://dx.doi.org/10.13005/ojc/350311
}

(Received: April 15, 2019; Accepted: May 02, 2019)

\begin{abstract}
Bitumen is used worldwide in the construction of flexible pavements and because of its wide applicability its performance is needed to be improved in all regards like, chemical and thermal stability, fatigue life, moisture susceptibility, mechanical strength, temperature susceptibility, rutting resistance, ageing resistance, tensile strength, viscosity, stiffness etc. In this connection, researchers have used various modifiers to improve the pavement performance. The present paper provides a brief review of different modifiers in road making industry. Some popular polymer modifiers like low density polythene, high density polythene, polypropylene, ethyl vinyl acetate, styrene butadiene styrene and industrial waste are reviewed in terms of their role in bitumen modification. It also discusses enhancement in properties of bitumen after modification in order to improve properties of pavement. Through the reviewed literature, it is found that the addition of the polymers to bitumen tends to enhance fatigue and cracking resistance mainly. The future development and recommendation in modifiers for bitumen modification are also suggested in the end.
\end{abstract}

Keywords: Modified Bitumen, LDPE and HDPE based bitumen modification, Bitumen modification by Industrial Polymer Waste.

\section{INTRODUCTION}

Bitumen is a complex colloid obtained as a last residue by fractional distillation of crude petroleum, consisting of four main chemical components saturates, asphaltenes, resins, aromatics (SARA). If we change relative composition of any one of these components, this can change entire structure and rheology of bitumen ${ }^{1}$. Bitumen is a famous choice as a binder in road construction material because of its wonderful properties like excellent binding features, water proofing properties and low $\operatorname{cost}^{2}$. But, with the tremendous increase in population, load on road transportation is increased. Moreover there are geographical areas where temperature rises up to $50^{\circ} \mathrm{C}$ and falls to $-5^{\circ} \mathrm{C}$. Now due to combined effect of heavy traffic and adverse climatic conditions life of roads laid with

This is an Open Access article licensed under a Creative Commons license: Attribution 4.0 International (CC- BY). Published by Oriental Scientific Publishing Company @ 2018 
neat bitumen gets decreased with the passage of time and it suffers from serious defects. The most common pavement defects are: (a) Rutting or permanent deformation ${ }^{3}$, (b) Thermal cracking ${ }^{4}$, (c) Fatigue cracking ${ }^{2}$ (d) Pothole formation etc. Rutting and cracking is shown below in Fig. 1. These defects not only reduce the performance of the pavement but also pose a safety hazard for the passengers.

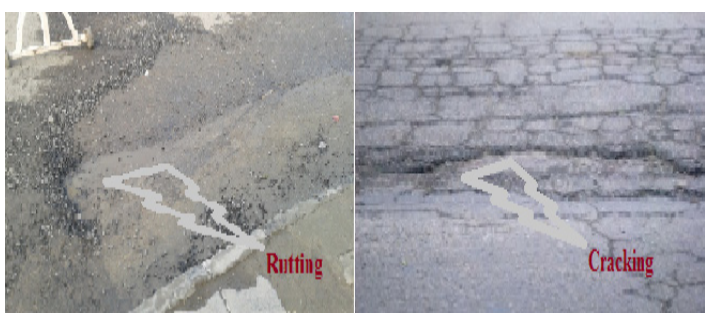

Fig. 1. Figure showing some pavement defects

Because of the need of modification of bitumen, large variety of modifiers has been reported in literature ${ }^{5-8}$. In order to increase the life span of road, researchers have tried to modify different properties of bitumen with the help of large variety of modifiers such as polymers, rubber, fibres, nanoparticles etc. The modifier have to satisfy some basic properties such as easy availability, good mixing characteristics with bitumen, low viscosity at higher temperature and high brittleness at lower temperature, enhancement of mechanical, chemical, thermal properties and photolytic stability and low cost of application.

Polymers used for bitumen modification can be grouped into three main categories: plastomers like EVA (ethylene-vinyl-acetate as most common), thermoplastic elastomers like SBS (styrenebutadiene-styrene being the most used), and reactive polymers ${ }^{9-10}$. Globally the polymer usage consists of $75 \%$ elastomeric modified bitumen, $15 \%$ plastomeric and rest $10 \%$ consists of either rubber or other modifiers ${ }^{11}$.
Different researchers have proved that plastomeric polymers are good in improving the rut resistance but elastomers are better than them as later exhibit high percentage of elastic recovery becomes insoluble in solvents \& infusible when melted and more resistant to harm caused by Ageing factors ${ }^{12-13}$. Moreover, plastomeric polymers are not able to enhance low-temperature performance of asphalt. On the other side, elastomers can enhance fatigue resistance and cracking resistance but it is not good in enhancing the heat resistance. Thus, it is justified to add up the benefits of plastomeric polymer and elastomers and then using these hybrid materials into asphalt as a modifier. This would be an alternative way of recycling waste polymer to improve the properties of asphalt pavement ${ }^{[14-18}$. Recycled EVA tends to enhance properties of bitumen at both high and low in-service temperatures. In addition it is an environment-friendly method for disposal of waste plastics ${ }^{19}$.

Some researchers have explored the use of different types of fibers (such as cellulose fiber, polyester fiber and mineral fiber) as modifier in asphalt mixtures ${ }^{20,21}$.

Recently researchers have also shown that nanoparticles also improve the properties of bitumen ${ }^{22}$. Bitumen modification with different modifiers can enhance the performance of roads ${ }^{23}$ and the most suitable method for modification is blending the bitumen with the modifier ${ }^{24}$.

\section{Different modifiers in bitumen and performances Polymers as modifier}

Researchers have tried long list of polymers as modifiers in bitumen. Each polymer tends to enhance one or other property of bitumen. They found that life of pavement can be enhanced by using even small amount of polymers ${ }^{25}$.

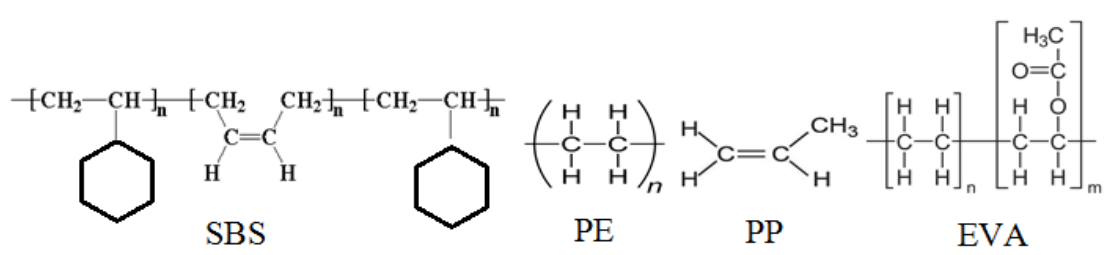

Fig. 2. Structural formula of different polymers used as modifiers in bitumen

Panda and Mazumdar examined the effect of reclaimed polythene derived from low density polythene (LDPE) and synthesized four modified asphalts by mixing reclaimed polythene 
(2.5\%, $5.0 \%, 7.5 \%$ and $10.0 \%$ content by weight of asphalt) with base asphalt $80 / 100$. They found that different percentages of polythene require different temperatures of mixing. The results indicated that the reclaimed polythene as a modifier tends to enhance marshal stability, resilient modulus, fatigue life and moisture susceptibility of mixes. Asphalt modified with the $2.5 \%$ reclaimed polythene was the optimally modified asphalt ${ }^{26}$. Auden, Sandoval, Jerez, Navaroo, Martinez, Partal, and Gallegos studied the effect of polymer concentration on the rheological and thermal properties of recycled polythene (RPE) modified bitumen. They synthesized blends of bitumen at $180^{\circ} \mathrm{C}$ in an open reactor on the different weight percentage of recycled polymer taken $(2.0 \%, 5.0 \%, 15.0 \%, 25.0 \%, 50.0 \% \mathrm{wt} \%)$. They concluded that recycled polythene tends to enhance the rheological and mechanical properties of bitumen. This leads to have greater resistance against rutting, thermal and fatigue cracking. Moreover low recycled polythene concentration (up to $5.0 \mathrm{wt} \%$ ) were found suitable for binders in road applications and high concentration (up to 15.0 $w t \%)$ for binders in roofing applications ${ }^{27}$. Use of pyrolysis polythene as a modifier was studied by Al hadidy and Yi-Qiu. For the purpose, pyrolysis LDPE was produced by means of thermal degradation and converted to powder by mechanical grinding and mixed pyrolysis LDPE in different percentages (2.0\%, 4.0\%, 6.0\%, 8.0\% by weight of asphalt) at $160^{\circ} \mathrm{C}$ with high speed stirrer at $1750 \mathrm{rpm}$ for 3-5 minute. They found that LDPE modified asphalt mixtures can perform well at low temperature, high temperature and intense rain zone and found that addition of $6.0 \%$ pyrolysis LDPE result in durable, cheaper and high performing roads ${ }^{28}$.

Lepe, Martinez and Gallegos studied the effect of concentration of HDPE on microstructure and rheological properties of modified bitumen using morphological analysis, differential scanning calorimetry (DSC) and linear viscoelastic measurement tests etc. They concluded that HDPE enhances the mechanical properties of bitumen and with 3\% HDPE binder structure changes to gel like, thus giving more elastic properties ${ }^{29}$. Hinislioglu and Agar conducted a research on high density polythene (HDPE) as a modifier of asphalt. It was found that HDPE could improve Marshall Stability and Marshall Quotient and Optimum conditions were $4.0 \% \mathrm{HDPE}$ at $165^{\circ} \mathrm{C}$ of mixing temperature for
30 min of mixing time ${ }^{30}$. When HDPE was used in pellet form as a modifier (of 80/100 grade asphalt), it is found to decrease moisture susceptibility and temperature susceptibility of asphalt. 5.0\% HDPE content was recommended for improvement of asphalt performance in this regard ${ }^{31}$.

A comparative study was carried out by Habib, Kamaruddin, Napiah and Tan on the rheological properties of $80 / 100$ bitumen modified by linear LDPE, HDPE and polypropylene (PP). The outcomes showed that PP blends better as compare to LLDPE and HDPE. The addition of polymer tends to enhance viscosity of bitumen. Better results were obtained when polymer conc. was kept below 3.0\% ${ }^{32}$. In a separate study by Tapkin, Cevik and Usar, evaluate the effect of polypropylene as a modifier in 50/70 bitumen. The research indicated that polypropylene tends to enhance Marshall Stability and Marshall Quotient values, thus improving physical and mechanical properties of bitumen ${ }^{33}$. Another research program investigated the effect of pyrolisis polypropylene in 50/60 asphalt cement. PP was grinded to powder and then subjected to thermal degradation (pyrolysis). The study concluded that the PP decreases the temperature susceptibility of asphalt ${ }^{34}$.

Ameri, Mansourian and Sheikhmotevali studied relative performance of EVA modified bitumens. Modified bitumens were analyzed according to dynamic shear rheometer (DSR), bending beam rheometer (BBR), creep compliance test, dynamic creep test, indirect tensile strength test, indirect tensile fatigue test. The tests results indicated that EVA improves rutting and fatigue resistance of bitumen. EVA modified bitumens (2.0\% and $4.0 \%)$ have better low temperature cracking resistance as compare to original bitumen ${ }^{35}$. Singh and Kumar performed a comparative study on the effect of EVA, SBS and Crumb rubber (CR) as modifiers in 60/70 grade bitumen. They analyzed the effect of modifiers on physical and rheological properties of bitumen before and after ageing. The outcomes showed that these properties get enhanced with the increasing percentage of modifier. Experimentally, it can be stated that EVA as a modifier can be used at very high temperature and heavy traffic areas, SBS as a modifier can be used in all climates, CR as a modifier can be used in moderately high temperature zone and low cost roads. EVA proved to be having higher rutting resistance as compare to SBS and $\mathrm{CR}^{36}$. 
Some researchers believe that EVA as a modifier improves rheological properties of bitumen ${ }^{37}$.

In a separate study 50/70 grade bitumen was modified with five different percentages of SBS $(2.0 \%$ to $6.0 \%)$. The morphology of samples were characterized using fluorescence microscopy. The use of SBS as a modifier on the long and short term ageing parameters of HMA have been examined by indirect tensile strength (ITS) test. The results of research proved that addition of SBS improved the conventional and mechanical properties of bitumen. It was also reported that SBS as a modifier decreases the short and long term ageing of hot mix asphalt $(\mathrm{HMA})^{38}$. Singh, Kumar and Maurya investigated the effect of SBS on strength characteristics of hot asphalt mixes. The study concluded that there was enhancement in strength characteristics, rutting resistance and moisture susceptibility of modified mixes $^{39}$. Table 1 summarizes the enhancement in properties of bitumen using different polymers along with their conditions of preparation.

Table 1: Enhancement in properties of bitumen using different polymers alongwith their conditions of preparation $^{40}$

\begin{tabular}{|c|c|c|c|c|c|c|c|}
\hline $\begin{array}{l}\text { Type of } \\
\text { polymer }\end{array}$ & $\begin{array}{l}\% \text { of polymer by } \\
\text { weight of asphalt }\end{array}$ & $\begin{array}{l}\text { Bitumen } \\
\text { grade }\end{array}$ & $\begin{array}{l}\text { Temp of } \\
\text { mixing }\end{array}$ & $\begin{array}{l}\text { Speed of } \\
\text { stirring }\end{array}$ & $\begin{array}{l}\text { Time of } \\
\text { mixing }\end{array}$ & Change in property & $\begin{array}{c}\text { Reference } \\
\text { number }\end{array}$ \\
\hline & $2.50 \%$ & \multirow{3}{*}{$80-100$} & $160^{\circ} \mathrm{C}$ & \multirow{3}{*}{3000 rpm } & \multirow{3}{*}{$20 \min$} & Enhancement in moisture & \multirow{3}{*}{$26,27,28$} \\
\hline Low Density & $5.0 \%$ & & $170^{\circ} \mathrm{C}$ & & & susceptibility, rheological & \\
\hline Polythene & $\begin{array}{c}7.50 \% \\
10.00 \%\end{array}$ & & $\begin{array}{l}180^{\circ} \mathrm{C} \\
200^{\circ} \mathrm{C}\end{array}$ & & & and mechanical properties & \\
\hline $\begin{array}{l}\text { High Density } \\
\text { Polythene }\end{array}$ & $\begin{array}{l}4.00 \% \\
6.00 \% \\
8.00 \%\end{array}$ & $\begin{array}{l}\mathrm{AC}-20 / \\
80-100\end{array}$ & $\begin{array}{l}145^{\circ} \mathrm{C} \\
155^{\circ} \mathrm{C} \\
165^{\circ} \mathrm{C}\end{array}$ & 200rpm & $\begin{array}{l}5 \mathrm{~min} \\
15 \mathrm{~min} \\
30 \mathrm{~min}\end{array}$ & $\begin{array}{l}\text { Better resistance against } \\
\text { permanent deformation, } \\
\text { decrease temperature } \\
\text { susceptibility }\end{array}$ & $29,30,31$ \\
\hline Polypropylene & $\begin{array}{l}0.50 \% \\
1.00 \% \\
1.50 \% \\
2.00 \% \\
2.50 \% \\
3.00 \% \\
5.00 \%\end{array}$ & $\begin{array}{l}50 / 70 \\
\text { and } \\
50 / 60\end{array}$ & $160-170^{\circ} \mathrm{C}$ & 120 rpm & $1 \mathrm{~h}$ & $\begin{array}{l}\text { Improvement in physical } \\
\text { and mechanical properties, } \\
\text { Reduction in temperature } \\
\text { susceptibility }\end{array}$ & $32,33,34$ \\
\hline $\begin{array}{l}\text { Ethyl vinyl } \\
\text { Acetate }\end{array}$ & $\begin{array}{l}2.00 \% \\
4.00 \% \\
6.00 \%\end{array}$ & $60 / 70$ & $180^{\circ} \mathrm{C}$ & 125 rpm & $2 \mathrm{~h}$ & $\begin{array}{l}\text { Enhancement in rutting } \\
\text { resistance, fatigue } \\
\text { resistance and resistance } \\
\text { to moisture damage }\end{array}$ & $35,36,37,42$ \\
\hline $\begin{array}{l}\text { Styrene } \\
\text { butadiene }\end{array}$ & $\begin{array}{l}2.00 \% \\
5.00 \%\end{array}$ & $60 / 70$ & $175-180^{\circ} \mathrm{C}$ & $1550 \mathrm{rpm}$ & $55 \mathrm{~min}$ & $\begin{array}{l}\text { Enhancement in strength } \\
\text { characteristics, rutting } \\
\text { resistance, moisture }\end{array}$ & $36,38,39$ \\
\hline styrene & $8.00 \%$ & & & & & $\begin{array}{l}\text { susceptibility and minimizes } \\
\text { the short and long term ageing }\end{array}$ & \\
\hline
\end{tabular}

The problem of storing polymer modified bitumen for long periods at high temperature was solved by Giavarini, Fillips, Santarelli and Scarsella; when they synthesized stable polypropylene modified bitumen by adding polyphosphoric acid. The meaning of stability here is that the polymer and the bitumen should not separate or settle during storage for longer durations at temperatures upto $160^{\circ} \mathrm{C}$. Actually when bitumen is pretreated with small amount of polyphosphoric acid, the acid tends to enhance homogenization of polymer by changing the structure of bitumen from sol to $\mathrm{gel}^{41}$. Toraldo and Mariani studied the effect of polymers as additives for bituminous mixtures and used three dosages of LDPE and EVA polymers $(3.0 \%, 6.0 \%$, and $9.0 \%$ by weight of bitumen). They concluded that polymers decrease mixtures stiffness at low temperatures, enhance fatigue life at intermediate temperatures and decrease fatigue deformations at high temperatures. $9.0 \%$ of EVA shows maximum improvement in fatigue life ${ }^{42}$.

\section{Industrial wastes as modifier}

Haddadi, Saoula and Aitmokhtar tried to investigate the effect of industrial polymeric waste on mechanical properties of bitumen. Industrial 
waste was taken in four different percentages $1.0 \%, 3.0 \%, 5.0 \%$, and $7.0 \%$ by weight of bitumen. Modified bitumen samples were subjected to different conventional tests. The results of research proved that industrial waste as a modifier tends to enhance mechanical properties as well as resistance to permanent deformation of bitumen. It solved two fold purposes i.e. the problem of solid waste disposal and pavement with greater resistance to rutting is obtained ${ }^{43}$. Another study related to the effect of waste polymer modifier (WPM) on the mechanical properties of bituminous concrete mixtures was done by choosing nitrile rubber and waste polythene in 1:4 ratio. The research proved that bitumen mixtures having 8.0\% WPM as modifier were more resistant to water damage and less susceptible to rut deformation ${ }^{44}$. Waste polymeric packaging materials (WPPM) was used to solve problem of rutting in bituminous roads. Used waste milk bags and other HDPE based carry bags were when used as modifier in bitumen, the outcomes showed that WPPM as a modifier were more useful for preventing rutting and deformation in hot climate areas $^{45}$. Motlagh, Kiasat, Mirzaei and Birgani tried to enhance technical properties of asphalt pavements using waste polystyrene (PS) disposable dishes. In this study, waste PS was used in four different ways - added to bitumen, bitumen replaced with PS, added to aggregates, same sized soft aggregates replaced with PS. It is obtained by their study that problem of water percolation and drainage in asphalt surfaces can be removed using PS as a modifier ${ }^{46}$. Recycled polythene obtained from processing of waste plastic products as modifier results in enhancement of viscosity, cohesive strength, water and heat resistance of bitumen. There was decrease in rate of thermal ageing ${ }^{47}$. The effect of HDPE based plastic waste on the performance of asphalt mixes were also being studied. HDPE as a modifier tends to enhance resistance to water damage. The bitumen sample modified with $4.0 \%$ of HDPE was the optimum concentration in terms of stability values ${ }^{48}$. Another work investigated the reuse of reclaimed asphalt, used motor oil and waste HDPE in the creation of recycled asphalt mixtures. Here HDPE used to make the mixture stable while used motor oil act as renewing agent of reclaimed asphalt. The study proved that $7.5 \%$ of used motor oil and $4.0 \%$ of HDPE along with $50.0 \%$ of reclaimed asphalt are the optimum percentages and can be utilized as a modified additive in asphalt mixtures ${ }^{49}$. Cement, lime, waste pozzolans (Coal waste, coal waste ash, rice husk ash, fly ash, ground granulated blast furnace slag) were used as modifier in bitumen emulsion to improve the performance of recycled mixture. The research concluded that rutting resistance of recycled mixture bitumen emulsion was enhanced and waste pozzolan can be used as a modifier ${ }^{50}$. Polymers like EVA and LDPE can be considered as fascinating modifiers of bitumen at high service temperatures as these tend to form a polymer network within the modified bitumen. Polymer modified asphalts are costly, difficult to handle and sometimes immiscible and therefore efforts should be made for finding new modifiers.

\section{CONCLUSION}

Polymers are extremely useful and fascinating modifiers that enhance a number of properties of bitumen (as summarized in Table 1). They are also useful at high service temperatures because they form a polymer network within the modified bitumen. But, at the same time, polymer modified asphalts have some inherent drawbacks. They are very costly and sometimes incompatible with the bitumen due to which there is phase separation and hence difficulty in storage for longer periods of time. Therefore, efforts should be made for exploring new modifiers which are cheap and more compatible with bitumen. Moreover these should be recyclable and should perform for longer periods. Effort should be made to make these modifiers less temperature sensitive and more resistant to climatic variations. Special care should be taken to remove these issues in the future research.

\section{ACKNOWLEDGEMENT}

We acknowledge support provided by Lovely Professional University, Jalandhar, India.

\section{Conflict of Interest}

There is no conflict of interest among the authors. 


\section{REFERENCES}

1. Loeber, L.; Muller, G.; Morel, J.; Sutton, O. Fuel., 1988, 77, 1443-1450.

2. Mathew, T.V.; Rao, K.V.K. Introduction to Transportation Engineering., 2006, NPTEL Ch 23(23), 1.

3. Kandhal, P.S.; Cooley, L.A.Transportation Research Board, National Cooperative Highway Research Program Report., 2003, 508, 2.

4. Lu, X.; Isacsson, U.; Ekblad. J. Mater. Struct., 2003, 36, 652-656.

5. Zhang, H.;Wu, X.; Cao, D.; Zhang, Y.; HE, M. Constr. Build. Mater., 2013, 47, 192-198.

6. Vasudevan, R.; Nigam, S. K.; Velkennedy, R.; Chandra, Sekar. A.R.; Sundarakannan, B. Preceedings of the International Conference on Sustainable Solid Waste Management., 2007, 21, 105-111

7. Punith, V.S.;Veeraragavan, A.; Amirkhanian, S.N. Int. J. Pavement Res. Technol., 2011, 4, 1-10.

8. Cuadri, A.A.; Garcia - Morales. M.; Navarro, F. J.; Partal, P. Fuel., 2014, 118, 83-90.

9. Saboo, N.; Kumar, P. Transportation Research Procedia., 2016, 17, 98-106.

10. Celoglu, M.E.; Yalcin, E.; Kok, B.V.; Alatas, T.; Norambuena-Conteras, J.; Garcia, A.; Yilmaz, M. Int. J. Pave. Eng., 2018, 1-10.

11. Airey, G. Fuel., 2003, 22, 1709-1719.

12. Xiang, L.; Cheng, J.; Que, J. Constr. Build. Mater., 2009, 23, 3586-3590.

13. Navarro, F.J.; Partal,P.; Martinez-Boza, F.J.; Gallegos, C.; J. Appl. Polym. Sci., 2007, 104, 1683-1691.

14. Yeh, P.H.; Nien, Y.H.; Chen, J.H.; Chen,W.C.; Chen, J. S. Polym. Engg. Sci., 2005, 45, 1152-1158.

15. Hernandez, G.; Medina, E.M.; Sanchez, R.; Mendoza, A. M. Energy Fuels., 2006, 20, 2623-2626.

16. Nien, Y.H.;Yeh, P.H.; Chen, W.C.; Liu, W.T.; Chen, J. H. Polym. Composites., 2008, 29, 518-524.

17. Martinez-Estrada, A.; Chavez-Castellanos, A.E.; Herrera-Alonso, M.; Herrera-Najera, R. J. Appl. Polym. Sci., 2009, 115, 3409-3422.

18. Fu, H.; Xie, L.; Dou, D.; Li, L.; Yu, M.; Yao, S. Constr. Build. Mater., 2007, 21, 1528-1533.

19. Garcia-Morales, M.; Partal, P.; Navarro, F.J.;
Martinez-Boza, F.; Gallegos, C. Energy fuels., 2004, 18, 357-364.

20. Moussa, G.K. Alex. Eng. J., 2003, 42, 329-336.

21. Tayfur, S.; Ozen, H.; Aksoy, A. Constr. Build. Mater., 2007, 21, 328-337.

22. Xiao, F.;Amirkhanian, A.N.; Amirkhanian, S.N. Inter. J. of Pavement Engg., 2011, 12, 533-541.

23. Martin. J.; Baumgardner. G.;. Hanrahan. J. Asphalt., 2006, 21, 14-16.

24. Gonzalez, O.; Pena, J.J.; Munoz, M.E.; Sanatmaria, A.; Perez-Lepe, A.; MartinezBoza, F.; Gallegos, C. Energy Fuel., 2002, 16, 1256-1263.

25. Hesb, S.A.M.; Woodhams, R.T. Coll. Polym. Sci., 1991, 269, 825-834.

26. Panda, M.; Mazumdar, M. J. Mater. Civ. Eng., 2002, 14, 527-530.

27. Fuentes-Auden, C.; Sandoval, J.A.; Jerez, A.; Navarro, F.J.; Martinez-Boza, F.J.; Partal, P.;Gallegos, C. Poly. Test., 2008, 27, 1005-1012.

28. Al-Hadidy, A.I.;Yi-qiu, T. Constr. Build. Mater., 2009, 23, 1456-1464.

29. Perez-Lepe, A.; Martinez-Boza, F.J.; Gallegos, C.; Energy fuels., 2005, 19, 1148-1152.

30. Hinislioglu, S.; Agar, E.; Mater. Lett., 2004, 58, 267-271.

31. Attaelmanan, M.; Feng, C.P.; Al-hadidy, A.I.; Constr. Build. Mater., 2011, 25, 2764-2770.

32. Habib, N.Z.; Kamaruddin, I.; Napiah, M.; Tan, I.M. Int. J. Civ. Env. Eng., 2011, 3, 96-100.

33. Tapkin, S.; Cevik, A.; Usar, U.; Expert Sys. Appl., 2010, 37, 4660-4670.

34. Al-Hadidy, A.I.; Yi-qiu, T.; Mater. Des., 2009, 30, 1133-1140.

35. Ameri, M.; Mansourian, A.; Sheikhmotevali, A.H.; Constr. Bulid. Mater., 2013, 40, 438-447.

36. Singh, M.; Kumar, P.; $25^{\text {th }}$ ARRB ConferenceShaping the Future: Linking policy, research and outcomes. Perth, Australia., 2012.

37. Kumar, P.; Mehndiratta, H.C.; Singh, K.L. J. Mater. Civil Eng., 2010, 22, 978-984.

38. Sengoz. B.; Isikyakar. G. J.;Hazard. Mater., 2008, 150, 424-432.

39. Singh, M.; Kumar. P.; Maurya, M.R.; Constr. Build. Mater., 2013, 41, 815-823. 
40. Beker, Y.; Mendez, M.P.; Rodriguez ,Y. Vis. Techno., 2001, 9, 39-49.

41. Giavarini, C.; Filippis, P.D.;Santarelli, M.L.; Scarsella, M. Fuel., 1996, 75, 681-686.

42. Toraldo, E.; Mariani, E. Constr. Build. Mater., 2014, 65, 38-42.

43. Haddadi, S.; Saoula, S.; Aitmokhtar, K.; International Conference on construction and building technology., 2008, 30, 333-346.

44. Sangita.; Khan, T.A.; Sabina.; Sharma, D.K.; Constr. Build. Mater., 2011, 25, 3841-3848.
45. Jain, P.K.; Kumar, S.; Sengupta, J.B. Indian J. Engg. Mater. Sci., 2011, 18, 233-238.

46. Motlagh, A.A.; Kiasat, A.; Mirzaei, E.; Birgani, F.O. World Appl. Sci. J., 2012, 18, 605-612.

47. Kishchynskyi, S.; Nagaychuk, V.; Bezuglyi, A.; Procedia Engg., 2016, 143, 119-127.

48. Kofteci, S.; Proced. Engg., 2016, 161, 1268-1274.

49. Abreu, L.P.F.; Oliveria, J.R.M.; Silva, H.M.R.D.; Fonseca, P.V. Constr. Build. Mater., 2015, 84, 230-238.

50. Ayar, P. Constr. Build. Mater., 2018, 178, 551-561 